\title{
Realities Regarding the (Non)Enactment of the Education Sector HIV and AIDS Policy in Rural Lesotho
}

\author{
Kelello Rakolobe \\ ORCID iD: https://orcid.org/0000-0002-4852-7587
}

Kevin Teise

ORCID iD: https://orcid.org/0000-0002-5861-1969

\begin{abstract}
In Lesotho HIV and AIDS is a national crisis with many rural citizens being either affected by or infected with HIV and AIDS. So severe is the rate of infections that HIV prevalence since 2013 has increased from 23 percent to 25 percent, making Lesotho the country with the second highest HIV and AIDS infections worldwide. Of these infections, a substantial percentage is young people. However, learners are also variously affected by the pandemic. Education is generally regarded as a significant factor in the fight against HIV and AIDS. Thus, Lesotho developed the Lesotho Education Sector HIV and AIDS Policy in 2012, which articulates the education sector's response to the HIV and AIDS crisis. It is against this backdrop that this article reports on a study conducted to explore the realities regarding the (non)enactment of the LESHAP (2012) in particular schools in the rural areas of Lesotho. Data were generated through semi-structured interviews with various stakeholders in Lesotho education. Findings from the study suggest that the aims and objectives of the LESHAP (2012) might not be realised because of various factors which negatively impact its effective enactment. These factors include a lack of knowledge and training; a lack of school specific policies; culture; a lack of training; the absence of the policy at school; a lack of school specific HIV and AIDS policies; religious convictions; and the attitudes of teachers
\end{abstract}


about condoms. This paper concludes with recommendations aimed at enhancing the enactment of the LESHAP 2012.

Keywords: Lesotho education, HIV and AIDS, LESHAP 2012, education policy, policy implementation, policy enactment

\section{Introduction}

HIV and AIDS is a global health threat with 36.7 million people living with the disease globally, of which 1.8 million are children (UN 2016). An estimated 25.5 million people living with HIV are found in sub-Saharan Africa (UNAIDS 2016), despite various attempts aimed at reducing new infections. HIV and AIDS does not only negatively affect the livelihoods and futures of the youth as they appear to be the most affected, but it also threatens global development. The situation in Lesotho is no different, as a large number of the Lesotho population is living with or is affected by HIV. This according to the UNAIDS (2018: Gap Report), which estimates that more or less 320, 000 of the 2 million people in Lesotho live with HIV. So severe is the impact of HIV and AIDS on the Basotho people that it was declared a national disaster (Belle, Ferreira \& Jordaan 2013:1117; Nyaphisi \& Obioha 2015:84).

Education is considered crucial in the fight against HIV and AIDS (Coombe, 2002:25; Kelly 2002:3). UNESCO (2013:7) states that "if schools and the education fraternity are not utilised in the curbing of HIV and AIDS pandemic, Lesotho will for a long time struggle with this epidemic". Being the largest sector, as well as being strategically placed, education in Lesotho is both the hope for the eradication of HIV and AIDS, and a significant role player in the fight against HIV and AIDS.

By virtue of its obligation to the people of Lesotho and because of the responsibility placed upon education to play a prominent role in combating HIV and AIDS, the Ministry of Education and Training (MOET), not only incorporated HIV and AIDS education into its school curriculum (Khau 2016:99), but it also developed the Lesotho Education Sector HIV and AIDS Policy 2012 (LESHAP 2012). This policy aims to "prevent the further spread of the epidemic" (MOET 2012: Section 8). However, noble policy aims can be achieved only if conducive conditions exist or are created for its enactment. It is our contention that education can play a significant role in preventing the 
further spread of HIV and AIDS in Lesotho, only if the LESHAP 2012 is successfully implemented in Lesotho schools.

Studies conducted in Lesotho education looked at various HIV and AIDS related issues (cf. Hlalele \& Letsie 2011; Belle, Ferreira \& Jordaan 2013; Khau 2016). We could not trace any study focusing particularly on the enactment of the LESHAP 2012. Based on this silence in the literature, we deemed it relevant to explore the realities regarding the enactment of the LESHAP 2012 in particular schools in rural Lesotho.

In reporting our findings, we first give a contextual background to Lesotho. Having done this, we present a brief overview of the HIV and AIDS situation in Lesotho, as well as the HIV and AIDS macro policy framework that is supposed to respond to the HIV and AIDS crisis in the country. Finally, findings from the interviews concerning the enactment of the LESHAP 2012 are offered and discussed. This paper concludes with recommendations.

\section{The Lesotho Context}

The Kingdom of Lesotho is located in the southern part of Africa and it is landlocked by South Africa. It is a constitutional monarchy, which is currently under multiparty coalition leadership. Lesotho is both a member of the Southern African Development Community, as well as of the British Commonwealth of Nations (Tlali \& Jacobs 2017: 78). The country covers an area of 35,355 square kilometres which is mostly mountainous, and it has a population of about 1.911 million people, and a per capita income of US\$ $1,322.403$. The economy is small, with GDP in current prices of US\$2.527 billion growing at a 5\% average year on year rate (IMF 2014). The 2016 Human Development Report (UNDP 2016) locates Lesotho in the low human development category, because of its very low Human Development Index 0,497 .

Lesotho's education is primarily influenced by missionaries and British rule which variously introduced formal education to the Basotho (Tlali \& Jacobs 2017:87). So strong was the influence of missionaries on Lesotho education that a large percentage of Lesotho schools are still co-owned and controlled by various churches. Within these schools, education not only has a strong religious character but religion, to a large extent, also informs the value system of the Basotho people, which impacts on perceptions about how HIV and AIDS should be combatted. Together with MOET, churches in Lesotho 
are therefore very important partners in education and in the fight against HIV and AIDS.

\section{HIV and AIDS in Lesotho}

According to the Lesotho Times (27 November 2014) the HIV and AIDS pandemic is spreading rapidly among the youth aged between 15 and 24 as they refuse to engage in precautious and responsible sexual behaviour. Research also indicates that in Lesotho, 1 in every 10 people aged between 15 and 17 is living with HIV (UNFPA 2015:3). In addition, a study conducted by the Ministry of Health in 2011 indicates that 34 percent of children in Lesotho are orphans due to HIV and AIDS. HIV and AIDS infections have spiralled dramatically in recent years, to the extent that Lesotho is currently the country with the second highest HIV prevalence after Swaziland (UNAIDS 2016). Esther (2012:28) maintains that the pandemic has affected every level of society and that many of the development achievements of the post-colonial era are being eroded. Mohale's Hoek, where this study was conducted, also faces various HIV and AIDS related challenges. According to the Ministry of Health and Social Welfare, Mohale's Hoek had the fifth highest number of orphans due to HIV and AIDS (Kingdom of Lesotho 2010:170). These statistics paint a gloomy picture for future socio-economic development in Lesotho, especially since the youth are regarded as the future of the country. In addition, it also signals danger for Lesotho education, because HIV and AIDS directly affects education as it is responsible for teacher and learner absenteeism, the decline in school enrolment, and learner drop-out due to the illness of parents.

Furthermore, a large percentage of learners orphaned by HIV and AIDS means that the already weak economy of Lesotho is enfeebled even further as limited resources have to be stretched to cater for the orphans' needs (Kingdom of Lesotho 2014:14). With regard to education, the Lesotho Education Sector Strategic Plan 2005-2015 has identified HIV and AIDS as one of the critical challenges facing basic education in Lesotho, because of its impact on teachers (Kingdom of Lesotho 2005:43). To mitigate the impact of HIV and AIDS on education and on the development of Lesotho requires an elaborate policy framework with clear enactment strategies, and the will to implement these policies. 


\section{Lesotho HIV and AIDS Policy Framework}

Lesotho is a signatory to various international treaties and declarations aimed at combating HIV and AIDS. These treaties and strategies include the Sustainable Development Goals; the United Nations General Assembly Special Declaration of Commitment to HIV/AIDS (2001); the Abuja Declaration of Commitment for Action in the Fight against HIV/AIDS, Tuberculosis, and other Infectious Disease (2001); the 2003 Maseru Declaration and Commitment to HIV and AIDS in the SADC region; as well as the 2006 Brazzaville Declaration and commitment on scaling up towards Universal access to HIV and AIDS prevention, treatment, care and support in Africa by 2010 (Government of Lesotho 2006:xiii).

Informed by these treaties and declarations, Lesotho developed and adopted its own unique country specific, macro policy framework. This framework consists of policies, such as the Preventive Strategy to Combat HIV and ADS (1995) (Government of Lesotho 2006; xii). In addition, the government of Lesotho (GOL) also adopted the Policy Framework on HIV/AIDS Prevention, Control and Management of 2000; the amended National HIV and AIDS Policy (2006) and the Public Service HIV and AIDS Policy (2010).

To further strengthen the fight against HIV and AIDS, the MultiSectoral National AIDS Strategic Plan (2002), and the National HIV and AIDS Policy 2006 was sanctioned. Whereas the former aims at coordinating all HIV and AIDS activities by Government Ministries and other interest groups, the latter aims to strengthen 'the implementation of the current HIV and AIDS interventions' (Government of Lesotho 2006:xiii). The National Aids Commission (NAC) was established with the sole purpose of coordinating Lesotho's HIV and AIDS responses. Although the NAC was disbanded in 2011, it was re-launched in 2015 (Kabi 2016:np). Over the years the GOL has also embarked on various projects aimed at increasing awareness about HIV and AIDS (Furin 2011:850). Currently, all Lesotho's policies and national plans are informed by the National Vision 2020 (2003). This Vision states that:

Lesotho shall be a stable democracy, a united and prosperous nation at peace with itself and its neighbours. It shall have a healthy and welldeveloped human resource base. Its economy will be strong, its environment well managed and its technology well established. 
Against this background, Lesotho developed the National Strategic Development Plan (NSDP) 2012/13-2016/17 as a medium-term enactment strategy. It is through the enactment of the NSDP that Lesotho also hopes to address the priorities as laid out in the Istanbul Programme of Action (2011), which amongst other things, also focuses in particularly on "improving health and combating HIV and AIDS" (UN 2011:24). Naidoo (2003:2) maintains that when states sign and ratify international conventions and draft national strategies, they automatically assume an operational responsibility to substantiate these in-principle commitments. Lesotho is therefore obliged and have a moral responsibility to not only implement these conventions and national plans or policies, but also to create conducive conditions for its effective enactment.

Although the existence of an elaborate policy framework signals a commitment from the Lesotho government to effectively combat HIV and AIDS, perceptions suggest the opposite. Olown (2014:6321) opines that although the Government of Lesotho has tried to respond positively to the HIV and AIDS pandemic, most of their efforts remain at the stage of policy statements and have never actually been practically implemented. Tlali and Jacobs (2017:86) also maintain that policy enactment in Lesotho is frustrated by a lack of logistical support. The mere fact that a number of policies exist does not guarantee that those policies are implemented, let alone effectively implemented. Rather, what is required is a sincere commitment on the part of the Lesotho government to ensure that policies are effectively implemented, and thus solve social problems or HIV and AIDS challenges, with which the country is faced.

\section{Policy Enactment}

Whereas Imurana, Haruna and Kofi (2014:197) regard policy enactment as the operational stage of the policy process, where policy is translated into action with the hope of solving some public problem, Ahmad, Rauf, Imdadullah and Zeb (2012:241) regard it as the adoption of the policy at grassroots level. To therefore ensure that a policy is adopted and translated into action assumes that those responsible for the enactment of the policy are equipped to do so, and embrace the vision of the policy.

Although policies are supposed to change or regulate the lifestyles of individuals (De Coning, Cloete \& Wissink 2011:46), and to solve public 
problems (Ahmad, Rauf, Imdadullah \& Zeb 2012:241), Imurana, Haruna and Kofi (2014:196) claim that many policies in Africa face challenges in the enactment phase. This situation makes it difficult to address the major problems for which they are developed. Morah (in Meyer \& Cloete 2011:229) also views bad policy enactment as the major obstacle to development in developing countries. Ali (2006:5) in particular, ascribes the failure of educational policy in developing countries to the issue of poor enactment. While the LESHAP 2012 articulates the Lesotho education sector's response to the HIV and AIDS pandemic, the extent to which it will indeed realise its objectives is dependent on the effective enactment thereof. Since it cannot be assumed that policies will be (effectively) implemented, an empirical investigation into the enactment of the LESHAP 2012 is warranted.

\section{Research Strategy}

\section{Participants and Ethical Considerations}

This study adopted a qualitative research approach, and 9 participants consisting of 3 teachers, 3 principals and 3 school board members (SBM) representing 2 different church schools, as well as 1 government school, were purposively selected to take part. As proprietors of schools, churches are important partners in Lesotho education, thus their inclusion in the study. Participants were selected based on the assumption that they would serve as information rich sources (Bernard 2013:164). Ethical protocols were observed by ensuring that we received permission from the University of the Free State, the MOET, and from the participants. We also secured the trustworthiness of this study (Elmusharaf 2013), by ensuring that results are not contaminated in any way by research design errors, the bias of the researcher or misinterpretations of the data and the transcriptions.

\section{Data Sources}

Data were generated through semi-structured interviews. Apart from being flexible and providing for a friendly non-intimidating conversation (Creswell 2012:46), these interviews also required us to build trust with the participants, so that the likelihood of information being withheld was eliminated (Bernard 2013:180). Interviews were audio recorded with permission from the participants, and transcribed in order not to lose any information. Responses in 
Sesotho (the home language of the Basotho), were first translated into English by a Sesotho specialist. The interviews were analysed in search of particular themes.

\section{Data Analysis}

Data were analysed using thematic analysis. During this process we identified, analysed and interpreted data meanings using themes or codes (Braun, Clarke \& Terry 2015:95-113). The themes identified and around which the data will be reported on are: knowledge of the LESHAP 2012; training; religion and culture; school specific policies; partnerships and stakeholder involvement; and personal values and attitudes.

\section{Findings}

Although discussed separately, the themes presented below are interrelated and point to the realities that exist regarding the enactment of the LESHAP 2012 at some rural schools in Lesotho.

\section{Knowledge about LESHAP}

From the data it appears that some participants have no knowledge about the existence of the LESHAP 2012. This, according to SB members A and B who "do not know about it"; and SB member C who "as the relevant stakeholders, do not have any knowledge about it". These views are corroborated by principal A who also "don't know it kannete (honestly)" and principal C who replied "It's my first time to see it". Teachers also seem not to be informed of the LESHAP 2012: teachers A and C respectively indicated that they have "not yet come in contact with the policy" and "have never met [sic] it". Principal B and teacher B seem to be the only ones who have knowledge of the policy as they respectively indicated: "Yes, I have seen it" and "I have heard about it but I have never read it". That the policy might not have been widely communicated to schools is emphasised by principal $\mathrm{C}$ who stated "Except for you, I have never met another person who knows about this policy". The lack of knowledge about the policy could be linked to the possible nondissemination of the policy to schools. In this regard principal B indicated "No, I don't have the policy at school" and principal C who stated "MOET has never 
brought the policy to the school; I saw the policy for the first time when you brought it here at my school".

Because LESHAP 2012 appears not to have been disseminated, principals do "not know what it says schools should do to assist in decreasing HIV" (principal B), and SB members are "unable to ensure that it is implemented effectively in schools" (SB member C). Similarly, teacher B also claims that he/she "does not know what the policy says" and is therefore "not sure if it can be helpful in the fight against HIV in Lesotho".

\section{Training on Enactment}

The enactment of the LESHAP 2012 seems to be further affected by a lack of training on the policy and its enactment. Principal $\mathrm{C}$ claimed that they "have not received any training on the LESHAP 2012", and that "MOET has never talked about it in any meetings". This was supported by principal B who observed "I do not know anything regarding the implementation of the LESHAP 2012". These views were echoed by teachers A and C who respectively asserted that they "know nothing about its implementation" and "have not received any training on the implementation thereof".

Participant (teacher B) appeared frustrated when claiming that MOET "does not assist us in any way". The same level of frustration is visible in the responses of participant principal B: "[the] Ministry is not useful" and that of participant teacher B who "is not getting any support from MOET" and for whom the fight against HIV is consequently "not as effective as it should be". MOET's apparent ignorance is also visible in the words of another participant (principal B): "MOET does not even accompany the people from the Ministry of Health when they come to assist us in health and HIV related issues".

Consistent with the above, it appears that MOET is not evaluating or monitoring the enactment of the LESHAP 2012. This is confirmed by participant principal A who stated that "MOET does not monitor anything". That the LESHAP 2012 is not communicated or monitored could be ascribed to the lack of dedicated officials in MOET, as is evident from participant principal C: "MOET needs to have personnel dedicated to the dissemination and enactment of LESHAP 2012".

\section{Religion and Culture}

Amidst the lack of knowledge of and training on the LESHAP 2012, various 
religious and cultural factors also seem to impact on its effective enactment. Principal A appeared concerned that the "Government policy speaks about condoms [whilst] the church [policy] is not allowing us to talk about condoms". Teacher B confirmed that church policy does not support the use of condoms: "We never encourage the use of condoms ... we do not talk about it".

Furthermore, the data reveal certain cultural practices which also seem to influence the educational context within which LESHAP 2012 is implemented. Although culture does not allow them "to talk to children about sex" (principal A), teacher C feels that they are now forced to deviate from cultural practices, because government "asked the schools to talk to learners about being circumcised in hospitals, not in initiation schools". For SB member $\mathrm{B}$ this is against their culture "which encourages that men should be circumcised at initiation schools".

Furthermore, whilst some of the learners infected with HIV "believe it is witchcraft, and therefore do not go to health centres but consult traditional healers" (SB member B) cultural practices, such as polygamy also promotes the spread of HIV. SB member $\mathrm{C}$ also highlighted the practice where "the brother of a deceased person marries the widow" as problematic because "sometimes the husband died due to HIV and this promotes the pandemic".

\section{School-specific HIV and AIDS Policies}

From the responses it appears as if schools do not have school specific HIV and AIDS policies that either articulate the school's response to HIV and AIDS or facilitates the enactment of the LESHAP 2012. This is according to SB member B, who "has never seen one", and SB member C whose school does "not have a policy document". These responses are corroborated by principal B who "doesn't have a school based HIV policy"; and principal C who "doesn't have a school specific policy". The absence of school specific HIV and AIDS policies are confirmed by teacher $\mathrm{C}$ who seems not to have "any knowledge about such a policy" and teacher A whose school does "not yet have a school specific policy".

This said, some of the church schools do seem to "have the policy of the church" (principal A); however, this school specific policy is "in the possession of the principal" (SB member A). Similarly, although the school of teacher B also "has a school policy" he/she appears not to have that policy in class: "No I don't have it". 


\section{Personal Values and Attitudes}

The responses also suggest that the personal values of participants might influence the enactment of the LESHAP 2012, especially with regard to the distribution of condoms at schools. Whereas SB member A regarded condom distribution as a good thing - to make condoms available at school "because the learners are already sexually active"; SB member B "feels threatened by that suggestion" because "it is problematic [and] not an easy issue at all". SB member C also "doesn't know [because] it seems as if we are giving them permission to engage in sexual activities". Although principal $\mathrm{C}$ seems to believe that "the availability of condoms might help", principal B "doesn't encourage them to be at school". Principal A is also sceptical about the success of condoms in combating HIV and AIDS because "the condom did not help the country".

Similar mixed reactions were expressed by the teachers. Whereas teacher A objects to the distribution of condoms because they "are educating small learners" teacher C appeared aware that some of the learners they are teaching at primary school, are ready for sex. Objections to the distribution of condoms at schools were further informed by fears that learners "might want to experience and they will just use them" (principal B), and that it will be perceived as "a way of encouraging learners to freely have sex" (SB member B).

\section{Partnerships and Stakeholder Involvement}

Parents and learners appear not to be actively involved in decision-making about HIV and AIDS in schools. SB member C avers that "the parents are not included at all". The absence of parents in decision-making is that "parents here are reluctant to even attend meetings" (SB member A). Learners are similarly "not included [and] the teachers decide what they want to share with the learners" (SB member C), making learners "just recipients of information" (principal A).

\section{Discussion}

Policy enactment is regarded as "the final acid test for a policy to be successful" (Brynard, Cloete \& De Coning 2011:135). However, policy enactment is also a complex process that is influenced by various actors and 
variables. The success of policy enactment and the subsequent realisation of policy aims and objectives are therefore largely dependent on the recognition of the complex nature of policy enactment, and the concomitant responsibility to act in pursuance of the effective enactment of the policy. One way of implementing it is by ensuring that policies are disseminated and information about policies is communicated to all (Makinde 2005:63; Ahmed, Rauf, Imdadullah \& Zeb 2012:242; Mthethwa 2012:40).

This research revealed that the LESHAP 2012 was neither disseminated nor communicated to the participating rural schools. The lack of information about a policy not only creates confusion, it also creates a distance between the policy implementers and the beneficiaries, which leads to a disjuncture between policy and practice, with good policy intentions being ultimately hindered (UNESCO 2008:18). Thus, although the LESHAP 2012, specifies the basic principles to be pursued in attaining its explicit goals, a lack of information and non-communication about it will hamper its effective enactment, therefore preventing the Lesotho government from attaining the envisioned goals articulated in it and in national HIV and AIDS programmes and policies. Instead of aiding the fight against HIV and AIDS, the gap that is effectively created due to the non-dissemination and the subsequent nonenactment of LESHAP 2012, not only put learners and teachers in these schools in greater danger of contracting HIV and AIDS, but it also jeopardises Lesotho's macro policy response to HIV and AIDS, and the country's social and economic development.

In addition, whilst the enactment of the LESHAP 2012 could potentially provide persuasive leverage to improve existing HIV and AIDS education (Aggleton \& Tyrer 2003:17), in Lesotho the apparent nondissemination of the LESHAP 2012, might variously impact the effective execution of HIV and AIDS education. This is particularly true for rural schools where the Basotho tradition and culture still serves as the anchor of the community. The interviews revealed that some participants have reservations about MOET's stance towards particular cultural and religious convictions and practices as articulated in HIV and AIDS education. It also appears that the personal values of the participants influence their perceptions about HIV and AIDS and particular related topics, to the extent that resistance to the teaching of and about HIV and AIDS, is discerned. Research confirms that the orientation of teachers' personal values, and religious and cultural dictates, influence perceptions about the use and value of condoms in HIV and AIDS 
protection, as well as what can and cannot be said about sex and thus also about HIV and AIDS (Henning, Chunheui \& Sunil 2011:8; Smith, Kippax, Aggleton \& Tyrer 2003:17; Hartell in Chabilall 2012:122). It would therefore be detrimental to the effective enactment of the LESHAP 2012 and to HIV and AIDS education if these variables are not taken into consideration, and if the perceived tension as a result of this is not acknowledged. As implementers of the LESHAP 2012 and of HIV and AIDS education, rural teachers in Lesotho find themselves in a difficult moral dilemma: on the one hand they need to conform to cultural and religious norms and also stay true to their own value orientations; on the other hand, they have an equally important moral responsibility to teach about and implement policies on HIV and AIDS.

Teachers are key players in the facilitation of programme enactment and change (Swanepoel \& Booyse 2006:1), and in the improved enactment of HIV and AIDS education and policy. Teacher's adoption and enactment of HIV and AIDS policies are also strongly influenced by their attitudes and norms (Mathews, Boon, Flisher \& Schaalma 2006:388). The successful enactment of the LESHAP 2012 policy in Lesotho rural schools therefore hinges on the extent to which teachers are able to navigate between personal values, cultural and religious dictates, and policy pronouncements and expectations. This because personal values not only determine teachers' understanding of the policy, how it should be implemented, and what it aims to achieve but also their positioning on issues of HIV and AIDS. It is only through access to and training on policies where these issues are articulated, that educators can come to understandings that will enable a conducive positioning and thus an effective enactment of the LESHAP 2012. Walker (in Mufune 2008:147) concede that even though teachers are unprepared and lack confidence to teach sex education, training in the enactment of HIV and AIDS policies will assist them to appropriately respond, through sex education, to the disease and its impact in and on the school.

However, the enactment of the LESHAP 2012 also depends on its monitoring and evaluation. The LESHAP 2012 pronounces that "all policy implementation will be monitored, evaluated and reported on a regular basis to provide accurate and relevant management information to the sector" (MOET 2012: Section 7.8). Nevertheless, findings from the interviews suggest that in rural Lesotho schools, the enactment of the LESHAP 2012 is neither monitored nor evaluated. Monitoring and evaluation not only enhances policy enactment, but it is also the fulfilment of a responsibility that enables authorities to assist 
with capacity building and training (Mupa 2012). By monitoring and evaluating its enactment, an opportunity is created for MOET to identify particular enactment challenges, such as the fact that rural schools appear not to be in possession of the LESHAP 2012, and the conflict teachers experience between what the policy pronounces and what religion, culture and personal convictions dictate, and to propose remedies to ensure effective enactment. Monitoring would also provide information on the extent rural schools have school specific HIV and AIDS policies as directed by the LESHAP 2012. School specific HIV and AIDS policies are supposed to give operational effect to national policies (RSA-DoE 1999: Section 12(1). More so, it also creates a climate of equity and fairness, and sound school-community relations which are positively associated with teaching about HIV and AIDS (Henning, Chunheui \& Sunil 2011:7; Gatsi, Chikuvadze \& Mugijima 2016:34). Thus, whilst school specific policies can potentially contribute to creating a greater awareness for the LESHAP 2012, they could also contribute to creating a HIV and AIDS-friendly school environment and a school culture infused with the values of social justice. The value of school specific policies therefore lies in the potential they hold to articulate a school specific response to HIV and AIDS, together with making particular pronouncements on how social justice values and principles be lived out as they relate to those infected and affected by HIV and AIDS. Within such a context, prejudice against and the scourge of discrimination and marginalisation that people living with and are affected by HIV and AIDS are subjected to in schools and in society, might be mitigated.

Furthermore, the contribution learners could make towards the effective enactment of HIV and AIDS policies should not be disregarded. The LESHAP 2012 (MOET 2012: Section 7.4) encourages the involvement of learners in the fight against and in school's responses to HIV and AIDS. UNICEF (2002:32-33; UNGASS 2001) maintain that the involvement of young people is a precondition for successful HIV and AIDS management and has become a central pillar of international AIDS policy. However, the interviews suggest that in rural schools in Lesotho, learner involvement in HIV and AIDS related issues are non-existent. The involvement of young people and learners in HIV and AIDS related issues are even more pertinent because participation in all aspects of life is part of the package of human rights young people should enjoy and which is written into international policies and charters (UNICEF 2003). Moreover, because HIV and AIDS is a prominent health issue for young people (Campbell, Gibbs, Maimane, Nair \& Sibiya 
2009:94), and that learners are variously affected by it, the assumption is that they would be involved in the enactment of policies directed towards addressing HIV and AIDS. This is particularly relevant for Lesotho as a large number of the Basotho rural youth in particular, appear to be either infected with and affected or orphaned by HIV and AIDS. To exclude learners from decision-making about HIV and AIDS, as it appears from this research, not only amounts to a disregard for their basic rights and their voice, but it also contributes towards their social marginalisation. Since the fight against HIV and AIDS requires the involvement of all members of society, the silencing and marginalisation of learners holds the potential for distancing them from active participation in school and HIV and AIDS related issues. This not only erodes democratic practices and collective decision-making practices within the school context, but it also disempowers the rural learner.

\section{Conclusion}

The aim of this article was to explore the realities regarding the (non) enactment of the Education Sector HIV and AIDS Policy (LESHAP 2012) in rural Lesotho. The LESHAP 2012 was developed as the Lesotho educational response to the HIV and AIDS pandemic in the country. More specifically, it was developed to make schools, and rural schools in particular, safer spaces by minimising the risk of contracting HIV and AIDS at school. Whilst the assumption is that policies should be disseminated and communicated in order to enhance their enactment, in the case of Lesotho education it appears that the LESHAP 2012 has never been disseminated and/ or communicated to rural schools. The reality is therefore, that the LESHAP 2012 seems not to have been implemented in schools in rural Lesotho. Consequently, ideals articulated in the LESHAP 2012 will not be realised, and the Lesotho education sector will effectively not be contributing towards the fight against HIV and AIDS in the country. If the MOET is committed to fight HIV and AIDS through education, it should in all earnest, develop plans and strategies and implement the infrastructure to facilitate the LESHAP 2012 dissemination in schools and to train teachers and SB member's on the policy in order to ensure its effective enactment. Such training should be sensitive to the perceived tension between individual-, religious- and cultural values and pronouncements made in and expectations of the LESHAP 2012. 


\section{References}

Aggleton, P., E. Yankah \& M. Crewe 2011. Education and HIV/AIDS - 30 Years on. AIDS Education and Prevention 23,6: 495 - 507. Available at: https://scholar.google.co.za (Accessed on 15 August 2016.) https://doi.org/10.1521/aeap.2011.23.6.495

PMid:22201234

Ahmad, I., M. Rauf, Imdadullah \& A. Zeb 2012. Implementation Gaps in Educational Policies of Pakistan: Critical Analysis of Problems and the Way Forward. International Journal of Humanities and Social Sciences 2,21: 240 - 245.

Ali, A. 2006 Why does Policy Fail? Understanding the Problems of Policy Implementation in Pakistan - A Neuro-cognitive Perspective. International Studies in Educational Administration 34,10: 2 - 20.

Belle, J.A., S.B. Ferreira \& A. Jordaan 2013. Attitude of Lesotho Health Care Workers towards HIV/AIDS and the Impact on the Population Structure. African Health Sciences 13,4: 1117 - 1125.

https://doi.org/10.4314/ahs.v13i4.36

PMid:24940340 PMCid:PMC4056471

Bernard, R.H. 2013. Social Research Methods: Qualitative and Quantitative Approaches. Los Angeles: SAGE.

Braun, V., V. Clarke \& G. Terry 2015. Thematic Analysis. In Rohleder, P. \& Lyons, A. (eds.): Qualitative Research in Clinical and Health Psychology. Hampshire: Palgrave Macmillan. Available at:

https://books.google.co.ls

(Accessed on 18 August 2018.)

https://doi.org/10.1007/978-1-137-29105-9_7

PMid:25745417 PMCid:PMC4333861

Brynard, P. 2005. Policy Implementation: Lessons for Service Delivery. Journal of Public Administration 40,4: 649 - 664.

Brynard, P., F. Cloete \& D. de Coning 2011. Policy Implementation. In Cloete,

F. \& C. de Coning (eds.): Improving Public Policy: Theory, Practice and

Results. $3^{\text {rd }}$ Edition. Pretoria: Van Schaik Publishers.

Campbell, C., A. Gibbs, S. Maimane, Y. Nair \& Z. Sibiya 2009. Youth Participation in the Fight against AIDS in South Africa: From Policy to Practice. Journal of Youth Studies 12,1: 93 - 109.

https://doi.org/10.1080/13676260802345757 
Chabilall, J. 2012. Educator's Role in Developing Adolescent HIV/AIDS Knowledge and Attitudes within School Culture. South African Journal of Education 32:121 - 131. https://doi.org/10.15700/saje.v32n1a524

Coombe, C. 2002. Keeping the Education System Healthy: Managing the Impact of HIV/AIDS on Education in South Africa. Current Issues in Comparative Education 3,1: 15 - 27.

Creswell, J.W. 2012. Educational Research: Planning, Conducting and Evaluating Qualitative and Quantitative Research. $4^{\text {th }}$ Edition. Boston: Pearson.

De Coning, C., F. Cloete \& H. Wissink 2011. Theories and Models for Analysing Public Policy. In Cloete, F. and C. de Coning (eds.): Improving Public Policy: Theory, Practice and Results. $3^{\text {rd }}$ Edition. Pretoria: Van Schaik Publishers.

Elmusharaf, K. 2013. Introduction to Qualitative Research. (Training Course in Sexual and Reproductive Health Research Geneva.) Geneva: RCRU University of Medical Sciences and Technology Geneva. Available at: http://www.gfmer.ch/SRH-Course-2012/research-

methodology/Introduction-qualitative (Accessed on 2 June 2014.)

Esther, B.K. 2012. HIV/AIDS Vulnerability of Students at the National University of Lesotho. Unpublished MA degree. Bloemfontein: University of the Free State.

Furin, J. 2011. The Role of Traditional Healers in Community-based HIV Care in Rural Lesotho. Journal of Community Health 36: 849 - 856. Available at: https://www.scholar.google.co.za (Accessed on 11 February 2016.) https://doi.org/10.1007/s10900-011-9385-3

PMid:21374087

Gatsi, C., P. Chikuvadze \& S. Mugijima 2016. An Analysis of HIV and AIDS Spatial Awareness and Vulnerability Level with Specific Reference to Staff at One Polytechnic in Zimbabwe. Journal of Education and Practice 7,19: 30 - 38. Available at: https://eric.ed.gov (Accessed on 11 October 2018.)

Government of Lesotho 2006. National HIV and AIDS Policy. Maseru: National AIDS Commission.

Government of Lesotho 2003. Lesotho Vision 2020. Maseru: Government Printing.

Henning, M., C. Chunheui \& K. Sunil 2011. Factors Associated with School Teachers' Perceived Needs and Level of Adoption of HIV Prevention 
Education in Lusaka. Zambia. International Electronic Journal of Health Education 14: 1 - 15. Available at: https://eric.ed.gov (Accessed on 11 October 2018) https://doi.org/10.1186/1475-9276-11-S1-A4

PMCid:PMC3287452

Hlalele, D. \& R. Letsie 2011. Gender Inequality and HIV/AIDS in Lesotho: A Human Ecological Perspective. Journal of Human Ecology 36: 159 - 165. https://doi.org/10.1080/09709274.2011.11906430

IMF - International Monetary Fund 2014. World Economic Outlook Database. Available at: https://www.imf.org/en/publications/weo (Accessed on 24 July 2018.)

Imurana, B.A., R.K. Haruna \& A-B.N. Kofi 2014. The Politics of Public Policy and Problems of Implementation in Africa: An Appraisal of Ghana's National Health Insurance Scheme in Ga East District. International Journal of Humanities and Social Science 4,4: 196 - 207.

Kabi, P. 2016. Lesotho's HIV Prevalence Rate Increases to 25 Percent. Lesotho Times June 17, 2016. Available at: https://www.lestimes.co.ls (Accessed on 20 June 2017.)

Kelly, M. 2002. Preventing HIV Transmission through Education. Perspectives in Education 20,2: 1 - 12.

Khau, M. 2016. Journeying into the Past: Lesotho Sexuality Education Curriculum History. Southern African Review of Education 22: 98 - 114. MOET Kingdom of Lesotho 2012. Lesotho Education Sector HIV and AIDS Policy. Maseru: Epic Printers.

Kingdom of Lesotho 2010. Lesotho Demographic Health Survey 2009. Claverton: ICF Macro.

Kingdom of Lesotho 2005. Education Sector Strategic Plan 2005 - 2015. Maseru: Government Printing.

Kingdom of Lesotho 2014. Demographic and Health Survey. Maseru: Government Printing.

Lesotho Times 2014. Basotho are no Longer Afraid of HIV. Available at: www.lestimes.co.ls (Accessed on 19 January 2016.)

Makinde, T. 2005. Problems of Policy Implementation in Developing Nations:

The Nigerian Experience. Journal of Social Sciences 11,1: 63 - 69.

https://doi.org/10.1080/09718923.2005.11892495

Mathews, C., H. Boon, A.J. Flisher \& H.P. Schaalma 2006. Factors Associated with Teachers' Implementation of HIV/ AIDS Education in Secondary Schools in Cape Town, South Africa. AIDS Care 18,4: 388 - 397. 
https://doi.org/10.1080/09540120500498203 PMid:16809118

Meyer, I. \& F. Cloete 2011. Policy Dynamics, Change, Failure and Success. In

Cloete, F. \& C. de Coning (eds.): Improving Public Policy: Theory, Practice and Results. ${ }^{\text {rd }}$ Edition. Pretoria: Van Schaik Publishers.

Ministry of Health 2015. Lesotho Demographic and Health Survey. Maseru: Government Printing.

Ministry of Health and Social Welfare 2010. Lesotho Demographic Health Survey 2009. Claverton: ICF Macro.

Mthethwa, R.M. 2012. Critical Dimensions for Policy Implementation. African Journal of Public Affairs 5,2: 36 - 47.

Mufune, P. 2008. Stakeholder Perceptions and Attitudes towards Sexual and Reproductive Health Education in Namibia. Sex Education 8,2: 145 - 157. https://doi.org/10.1080/14681810801980961

Naidoo, V. 2003. A Human Rights Perspective on Policy: Implementation

Processes: Observations from the South African Public Sector. Available at: http://hdl.handle.net/20.500.11910/8255

Nyaphisi, M.B. \& E.E. Obioha 2015. Challenges of HIV and AIDS Related Community Home-based Health Care Delivery System in Roma Valley, Lesotho. Anthropological Notebooks 21,1: 83 - 105.

Oluwo, D. 2014. Poverty, Migration and the Incidence of HIV/AIDS among Rural Women in Lesotho: A Rights-based Approach to Public Health Strategies. Gender \& Behaviour 12,2: 6317 - 6328. Available at: https://www.scholar.google.com (Accessed on 11 April 2016.)

RSA - DoE 1999. National Policy on HIV/AIDS, for Learners and Educators in Public Schools, and Students and Educators in Further Education and Training Institutions. Pretoria: Government Printers.

Smith, G., S. Kippax, P. Aggleton \& P. Tyrer 2003. HIV/AIDS School-based Education in Selected Asia-Pacific Countries. Sex Education 3,1: 3 - 21. https://doi.org/10.1080/1468181032000052126

Swanepoel, C. \& J. Booyse 2006. The Involvement of Teachers in School Change: A Comparison between the Views of School Principals in South Africa and Nine Other Countries. South African Journal of Education 26,2: 189 - 198.

Tlali, T. \& L. Jacobs 2017. Education System of Lesotho: Education in the Mountain Kingdom. In Wolhuter, C.C., L. Jacobs \& H.J. Steyn (eds.): Thinking about Education Systems. Potchefstroom: Noordbrug. 
UNAIDS 2016. Global AIDS Update. Available at: www.unaids.org (Accessed on 2 January 2017.)

UNAIDS 2018. Prevention Gap Report 2018. New York: UNAIDS.

UNDP 2016. Human Development for Everyone: Briefing Note for Countries on the 2016 Human Development Report. Human Development Report 2016. UNDP.

UNESCO 2008. Overview: Good Policy and Practice in HIV \& AIDS and Education. Paris: UNESCO.

UNESCO 2013. 2011 - 2012 Education Sector HIV and AIDS Global Progress Survey: Progression, Regression or Stagnation? Paris: UNESCO. Available at: https://www.google.co.za (Accessed on 14 December 2015.) UNFPA 2015. HIV Prevention in Lesotho. Available at: https://www.unfpa.org (Accessed on 19 January 2016.)

UNGASS 2001. Global Crisis - Global Action. New York: UN.

United Nations 2016. Programme of Action for the Least Developed Countries for the Decade 2011 - 2020. Istanbul: United Nations. Available at: https://www.un.org (Accessed on 11 October 2018.)

UNICEF 2003. The State of the World's Children 2003 - Child Participation. Geneva: UNICEF.

UNICEF 2002. Young People and HIV/AIDS: Opportunity in Crisis. New York: UNICEF.

Working Group on Higher Education 2006. Higher Education Institutions in Africa Region to HIV/AIDS. Accra: Development of Education in Africa.

Kevin Teise School of Education Sol Plaatje University Kevin.teise@spu.ac.za

Kelello A. Rakolobe (MED) Department of Educational Foundations National University of Lesotho 2009070539@ufs4life.ac.za 